\title{
Relationship between climate conditions and nosocomial infection rates
}

\author{
Chen $\mathrm{Y}^{1}$, Xu $\mathrm{X}^{2}$, Liang $\mathrm{J}^{3}$, ${ }^{\mathrm{L}}$ in $\mathrm{H}^{1}$
}

1. Department of Prevention and Health-care

2. Department of Stomatology, The Second Affiliated Hospital of Guangzhou Medical University, Guangzhou 510260, China

3. Guangdong Meteorological Observatory, Guangzhou 510080, China

\begin{abstract}
Background: Nosocomial infections constitute a global health problem.

Objective: To explore the relationship between nosocomial infection rates (NIRs) and climatic factors including temperature and relative humidity in Guangzhou area of China.

Methods: 30892 patients in our hospital in 2009 were investigated for nosocomial infection status, and the contemporaneous temperature and relative humidity were analyzed statistically. NIRs increased with relative humidity and temperature in central ICU and geriatric department.

Results: No statistical differences were found between each quarter of 2009 in the distribution of nosocomial infection sites. There were no statistical differences in the pathogenic species of nosocomial infections between high-temperature and low-temperature months in different departments. NIRs had a correlation with temperature and relative humidity in geriatric department and central ICU.

Conclusion: To decrease NIRs and improve health care quality, it is necessary to strengthen the control of temperature and humidity especially for geriatric department and central ICU.
\end{abstract}

Keywords: climate conditions, temperature, relative humidity, nosocomial infection

African Health Sciences 2013; 13(2): 339 - 343 http:/ /dx.doi.org/10.4314/ahs.v13i2.20

\section{Introduction}

With the development of modern medical techniques for diagnosis and treatment, heavy use of antibiotics and increased invasive tests and procedures, nosocomial infections constitute a global health problem. It leads to prolonged hospital stay, increased expenses and high mortality rates, causing severe economic losses to both patients and hospitals ${ }^{1}$. Many factors have effects on nosocomial infection, including host factors (age, diet, hormone level, etc.) and environmental factors (climatic characteristics, ventilation condition and medical sanitary conditions) $)^{2}$. However, it is still unclear how climate changes affect the occurrence of nosocomial infection. Guangzhou has a subtropical climate with special temperature and humidity. The average annual temperature in Guangzhou is about $22^{\circ} \mathrm{C}$ and the average temperature is as high as $13^{\circ} \mathrm{C}$ even in the

\section{*Corresponding author:}

Hongyan Lin

Department of Prevention and Health-care

The Second Affiliated Hospital of Guangzhou

Medical University

China

Email: hylingz@163.com coldest January. The mean annual rainfall amount in Guangzhou is about $1700 \mathrm{~mm}$ and the humidity is relatively high. In addition, the average annual wind velocity is only about $1.9 \mathrm{~m} / \mathrm{s}$. Based on the climate change in 2009, we conducted a retrospective study on nosocomial infections in the Second Affiliated Hospital of Guangzhou Medical College, to explore the relation between climate and NIRs.

It should be noted that, in some hospitals especially those in developing countries the wards are generally open and the temperature and humidity are not controlled. Furthermore, the humidity is often not well controlled in central ICU even if the temperature is controlled using air-conditioning. In other words, the wards are greatly affected or determined by the ambient conditions. Therefore, effects of ambient conditions were investigated, which may be helpful especially for hospitals in developing countries.

\section{Methods \\ Clinical data}

Combining with nosocomial infection data provided by clinicians, professional personnel performed a retrospective analysis of hospitalized patients from Jan. 1 st to Dec. 31st in 2009. Nosocomial infections 
in 30892 hospitalized patients were analyzed statistically, especially for NIRs, infection sites (ICU: central ICU; HD: Hematology department; GD: Geriatric department; ND: Neurology department) and pathogen classification in central ICU, hematology department, geriatric department and neurology department. The investigation received ethics approval from the Ethics Committee of The Second Affiliated Hospital of Guangzhou Medical University.

\section{Meteorological data}

Data of average monthly temperature and relative humidity in Guangzhou in 2009 were provided by Guangzhou meteorological bureau.

\section{Diagnostic criteria}

The diagnosis of nosocomial infection was made according to the hospital infection diagnostic criteria (2001) issued by People's Republic of China.3

\section{Statistical analysis}

Statistical analysis was executed by SPSS 14.0 software. Multiple regression analysis (partial correlation analysis) was used to assess average monthly temperature and relative humidity. Nosocomial infection sites in different quarters were analyzed based on variance analysis. Probability values
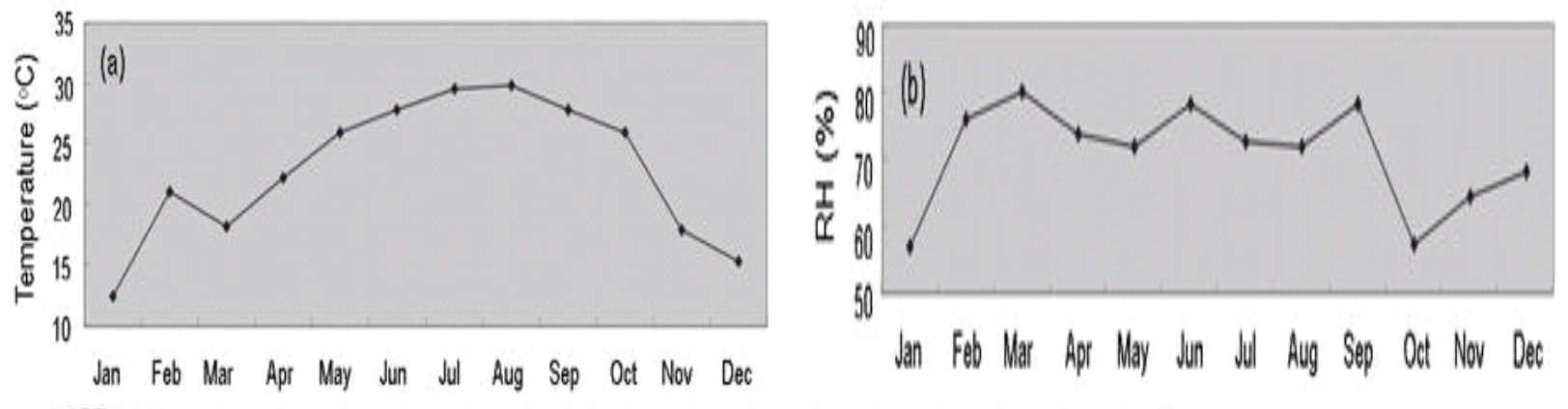

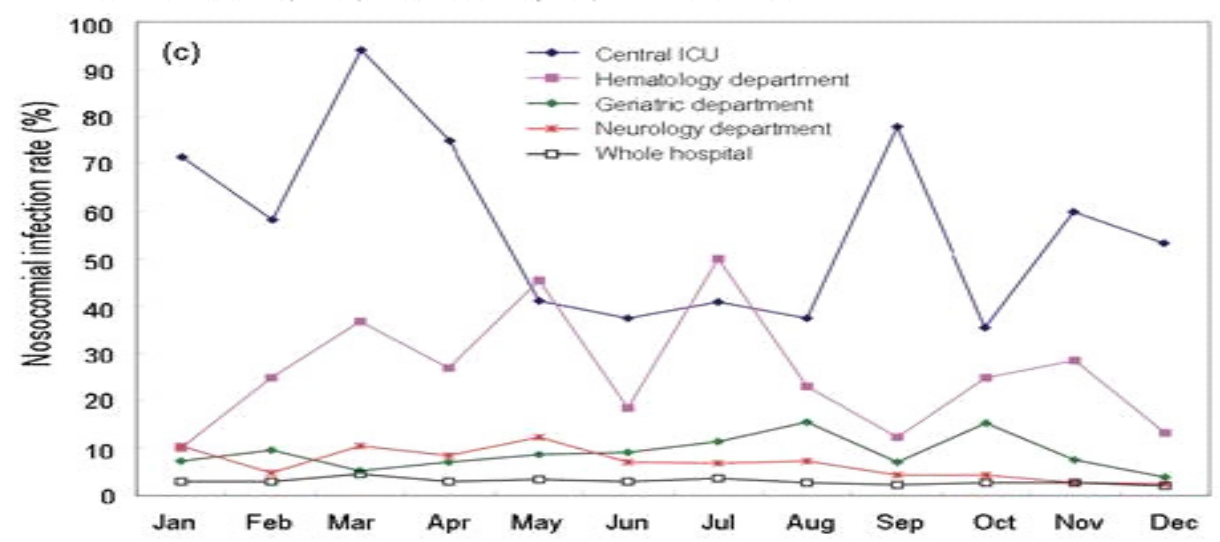

Figure 1: Average monthly temperature (a), relative humidity (b) andnosocomial infection rates (NIRs) (c) in 2009 among different departments 
Relation of nosocomial infection sites to temperature and relative humidity

Based on the special climate in Guangzhou, Nov., Dec. and Jan. are regarded as the same quarter, and the rest can be deduced accordingly. Mean temperature from the first to fourth quarter were $15.18^{\circ} \mathrm{C}, 20.43{ }^{\circ} \mathrm{C}, 27.71{ }^{\circ} \mathrm{C}, 27.84{ }^{\circ} \mathrm{C}$, and relative humidity were $63.38 \%, 76.67 \%, 74.27 \%, 69.23 \%$, respectively. There were no statistical differences between each quarter of 2009 in the distribution of nosocomial infection sites (upper respiratory infection, lower respiratory infection, urinary tract infection, other infections) ( $\mathrm{F}=12.557, \mathrm{P}=0.184$, figure 2).
High-temperature and low-temperature months in 2009 were separated to analyze the distribution of pathogenic species of nosocomial infections in central ICU, hematology department, geriatric department and neurology department as shown in table 1. Data were analyzed with the Chi-square method. No statistical differences were found in pathogen distribution between high-temperature and lowtemperature months in different departments $(\mathrm{p}>$ 0.05).

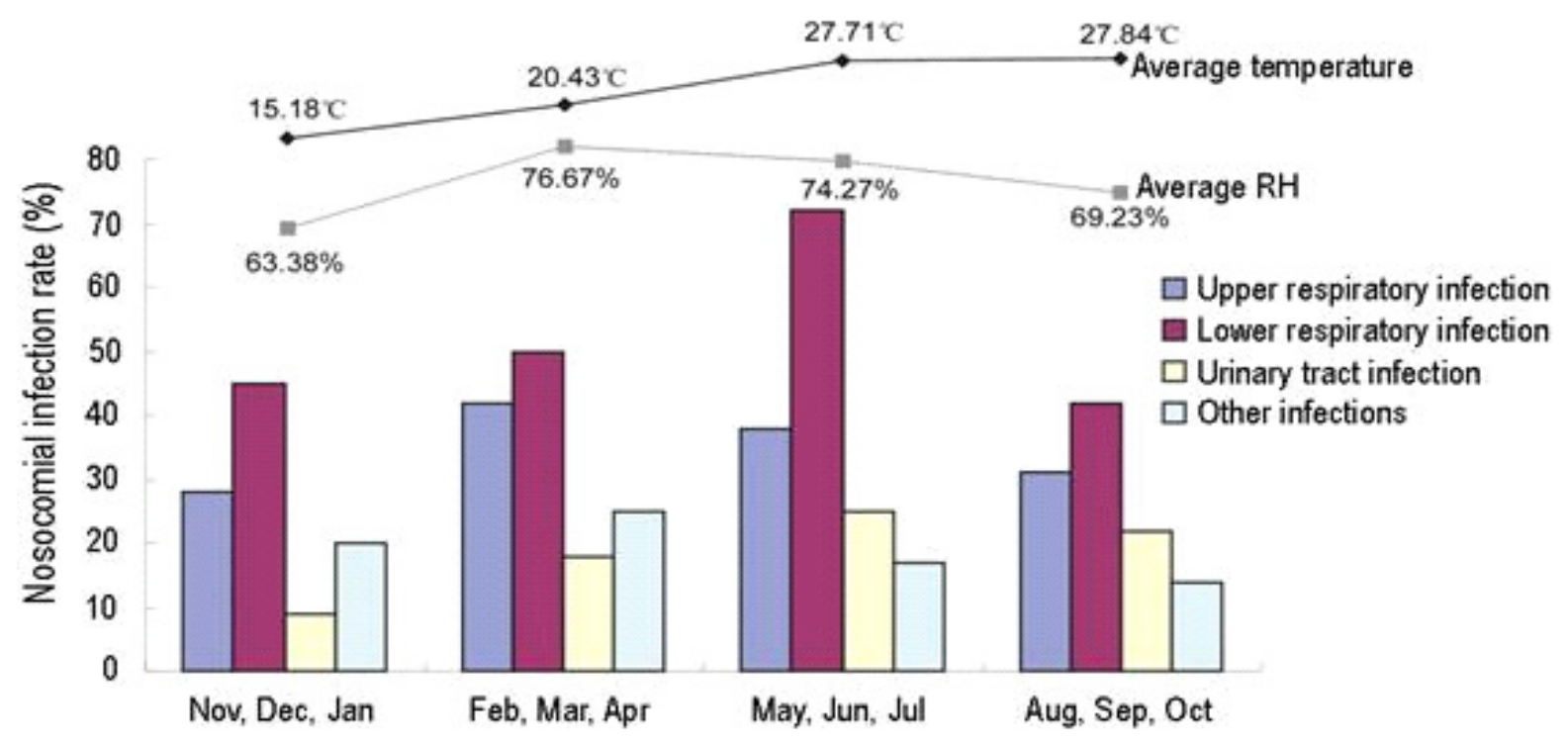

Figure 2: Relation of nosocomial infection sites to temperature and relative humidity

Table 1: Pathogen distribution of nosocomial infections in high-temperature and lowtemperature months of 2009 in different departments

\begin{tabular}{|c|c|c|c|c|c|c|c|c|}
\hline \multirow[t]{2}{*}{ Pathogenic species } & \multicolumn{4}{|c|}{$\begin{array}{l}\text { May to Dec. } \\
\text { (mean temperature } 27.78{ }^{\circ} \mathrm{C} \text {, mean } \\
\text { humidity } 71.75 \% \text { ) }\end{array}$} & \multicolumn{4}{|c|}{$\begin{array}{l}\text { Nov. to Apr. } \\
\text { (mean temperature } 17.80^{\circ} \mathrm{C} \text {, } \\
\text { mean humidity } 70.00 \% \text { ) }\end{array}$} \\
\hline & $\mathrm{ICU}$ & $\mathrm{HD}$ & GD & ND & ICU & $\mathrm{HD}$ & GD & $\mathrm{ND}$ \\
\hline Staphylococcus aureus & 8 & 2 & 1 & 13 & 21 & 0 & 1 & 8 \\
\hline Acinetobacter baumannii & 5 & 0 & 0 & 4 & 6 & 1 & 1 & 5 \\
\hline Pseudomonas aeruginosa & 3 & 0 & 2 & 4 & 5 & 1 & 2 & 6 \\
\hline Escherichia coli & 1 & 1 & 3 & 14 & 5 & 2 & 2 & 7 \\
\hline Klebsiella pneumoniae & 5 & 2 & 2 & 7 & 2 & 1 & 1 & 3 \\
\hline Candida albicans & 4 & 0 & 0 & 3 & 4 & 0 & 1 & 0 \\
\hline Stenotrophomonas maltophilia & 1 & 0 & 0 & 1 & 2 & 1 & 1 & 0 \\
\hline Yeasts & 2 & 1 & 0 & 0 & 1 & 1 & 0 & 0 \\
\hline Burkholderia cepacia & 4 & 0 & 0 & 0 & 2 & 1 & 0 & 0 \\
\hline Coagulase-negative staphylococci & 0 & 1 & 0 & 1 & 1 & 1 & 0 & 1 \\
\hline Total & 33 & 7 & 8 & 47 & 49 & 9 & 9 & 30 \\
\hline
\end{tabular}




\section{Discussion}

Nosocomial infection can be influenced by many factors, such as geography, climate, environment, economy and disease categories. ${ }^{4}$ Our study mainly explored the relation between NIRs and two climatic factors -temperature and relative humidity. We performed correlation analysis of average monthly temperature and relative humidity with NIRs in different departments.

It was found that NIRs had positive correlation with temperature and relative humidity in central ICU and geriatric department, but not in the whole hospital. That means that the effect of temperature and relative humidity on nosocomial infection is different in different wards. It should be noted that in central ICU, which is controlled at a constant temperature and good environment, most patients use respirators with an optimal setting temperature and humidity, and climate change factors have no substantial influence in this ward. ${ }^{5}$

However, in our study, nosocomial infection rates were found to have correlation with temperature and humidity in central ICU, which may be affected by other non-climatic factors and our relative small sample size. There is arelative high nosocomial infection rate in central ICU and most patients are severe, bedridden ones with poor physical fitness and impaired immune function, who are particularly vulnerable to infection. Therefore, temperature and humidity should not be considered as practical reasons for the fluctuation in nosocomial infection rates. In geriatric department, most common diseases are chronic heart and lung diseases, tumors and diabetes. The ward environment is more influenced by external climate conditions and gerontal patients are prone to respiratory infections for severe illness and poor resistance. ${ }^{6}$ As respiratory infections are mainly airborne, temperature and humidity are important influential factors for pathogen proliferation. Our study also suggested that external temperature and humidity have significant correlation with NIRs in geriatric department, and that NIRs increase with temperature and humidity.

Changes of many meteorological factors can promote pathogen propagation and spread, and induce decreased immune function of patients, leading to the occurrence of nosocomial infection. ${ }^{7}$ Temperature is a very important factor and has a complex influence on NIRs. Our study suggests that it is important to take full account of room temperature control in geriatric department, which mostly receive immunocompromised elderly patients. High or low temperature extremes and extremely low mean temperature are all detrimental to the human body. Air humidity is also an important factor and the reproductive capacity of pathogens increase with relative humidity. In China, Guangzhou has a relatively high level of relative humidity, especially in March and May with severe damp and mould problems. Therefore, excessive pathogen propagation caused by high relative humidity has great impact on patients with low immunity, and NIRs increase with relative humidity.

Many climatic factors, especially temperature, play important parts in the propagation and spread of pathogens. ${ }^{8}$ We performed further analysis and compared pathogen distributions between high-temperature and low-temperature months in Guangzhou. But no statistical differences were found between the two groups. However, no significant difference was found in average temperature between high-temperature and lowtemperature months. It should not be considered that temperature has no influence on pathogen distribution, but that seasonal climate conditions of Guangzhou have no significant effect on nosocomial infections.

Most common site for nosocomial infections is upper respiratory tract, following by lower respiratory tract, urinary tract, skin and soft tissue and gastrointestinal tract. According to the special climate, we found no statistical differences in different quarters in the distribution of nosocomial infection sites in Guangzhou. For the special climatic conditions in different quarters, it is speculated that climatic condition has no significant effect on NRIs. The occurrence of nosocomial infection is the result of interactions of external environmental and intraindividual factors. When the body condition is stable, the strength of external environmental factors determines NIRs. ${ }^{910}$ Guangzhou has special climatic conditions, the influence of which is unknown. Our study explored the relation of NIRs to temperature, relative humidity, disease category and ward environment, and studied the possible correlation of seasonalclimatic changes with nosocomial sites and pathogen distribution. We found a correlation of NIRs with temperature and relative humidity in geriatric department and central ICU. Therefore, it seems worthwhile to pay more attention to environmental condition control in these two departments. It is necessary to strengthen the control of ward temperature and humidity in order to decrease NRIs and improve health care quality. The 
seasonal climatic changes of Guangzhou have no influence on nosocomial infection sites and pathogen distribution. However, more detailed environment and climate factors are still worthy of further study, such as temperature difference, wind speed, rainfall amount and air convection.

\section{Conclusion}

In order to decrease NIRs, we should strengthen the control of environment and climate factors in many respects and make efforts on climate-specific prevention in high-risk departments and populations.

\section{References}

1. Lee J, Imanaka Y, Sekimoto M, Ikai H, Otsubo T. Healthcare-associated infections in acute ischaemic stroke patients from 36 Japanese hospitals: Risk-adjusted economic and clinical outcomes. Int J Stroke. 2011;6(1):16-24.

2. Eriksen J, Mujinja P, Warsame M, Nsimba S, Kouyate B, Gustafsson LL, Jahn A, Muller O, Sauerborn R, Tomson G. Effectiveness of a community intervention on malaria in rural Tanzania - a randomised controlled trial. Afr Health Sci. 2010;10(4):332-340.

3. Ma GX, Fu XY, Zhang L. Investigation and analysis of nosocomial infection prevalence. Chin I Nosocomiology. 2011;21(3):436-437.

4. Badiei Z, Khalesi M, Alami MH, Kianifar HR, Banihashem A, Farhangi H, Razavi AR. Risk factors associated with life-threatening infections in children with febrile neutropenia: A data mining approach. I Pediatr Hematol Oncol. 2011;33(1):e9-e12.

5. Marchesi I, Marchegiano P, Bargellini A, Cencetti S, Frezza G, Miselli M, Borella P. Effectiveness of different methods to control legionella in the water supply: Ten-year experience in an italian university hospital. J Hosp Infect. 2011;77(1):47-51.

6. Adams D, Yee L, Rimmer JA, Williams R, Martin H, Ovington C. Investigation and management of an a. Baumannii outbreak in icu. Br J Nurs. 2011;20(3):140, 142,144-147.

7. Kunze U. Tbe_-awareness and protection: The impact of epidemiology, changing lifestyle, and environmental factors. Wien Med Wochenschr. 2010;160(9-10):252-255.

8. Aggarwal R, Goel N, Chaudhary U, Kumar V, Ranjan KP. Evaluation of microbiocidal activity of superoxidized water on hospital isolates. Indian J Pathol Microbiol. 2010;53(4):757759.

9. Wan LS, Li JW, Ke BB, Xu ZK. Ordered microporous membranes templated by breath figures forsize-selective separation. $\mathrm{I} \mathrm{Am} \mathrm{Chem}$ Soc. 2012;134(1):95-98.

10. Selvaraj N. Artificial humidification for the mechanically ventilated patient. Nurs Stand. 2010;25(8):41-46. 